\section{WATER FLOSSER FOR SIGNIFICANT PLAQUE REMOVAL}

Since the inception of the first Waterpik water flosser, more than 50 years ago over 70 clinical trials have been published, and collectively they demonstrate significant plaque removal, reduction of gingival bleeding and reversal of gingivitis, says the manufacturer.

The Waterpik water flosser is a safe and effective adjunct that combines water pressure and pulsations to quickly and easily remove plaque and debris deep between the teeth as well as subgingivally, where floss and brushes cannot reach. For more information on Waterpik, visit www.waterpik.co.uk.

Waterpik products are available from Amazon, Asda, Costco UK, Boots.com and Superdrug stores across the UK and Ireland.

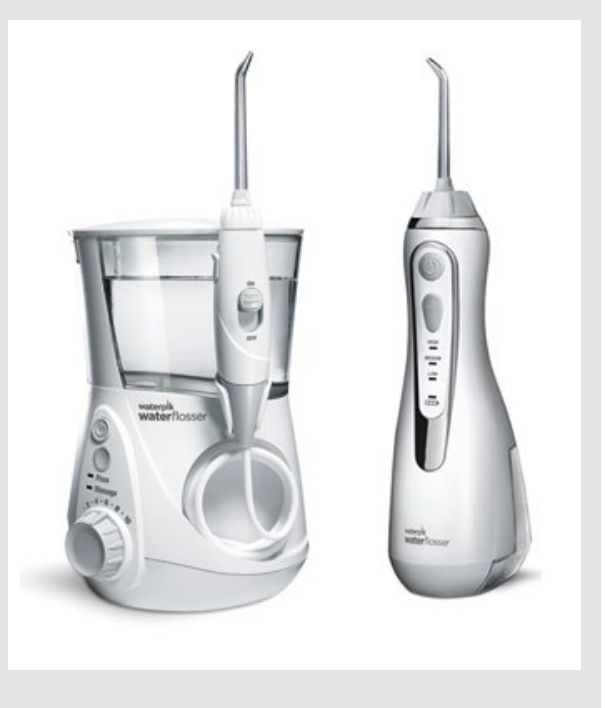

\section{ON THE WARPATH}

Dental Directory has won a multi-million pound four-year contract to replace and install dental equipment across the Ministry of Defence's estate. The contract will see Dental Directory become the sole supplier and installer of around 200 replacement A-dec dental chairs and almost 300 Acteon intraoral x-ray systems.

Its team of $60 \mathrm{UK}$-based engineers will install equipment in a variety of unusual locations on behalf of the Ministry of Defence, including warships and military bases. Scott Selbie, Technical Services Director for Dental Directory said: 'Many of our growing team of UK engineers have military experience and a working knowledge of the challenges these locations can bring to installation projects. It's an exciting contract and we're thrilled to be playing a part in it.'

The contract was won by Dental Directory following a competitive tender process and will run exclusively until 2023. For more information, visit www.dental-directory. co.uk.

\title{
EXPRESS TURNAROUND LABORATORY
}

Dental teams need to find a dental laboratory that can offer them a wide range of services and that will never let them down. Look no further than CosTech Dental Laboratory.

CosTech offers dentists a free personal pick-up and delivery service in around North Kent and South London. The team is dedicated to ensuring that standards remain high across the board with stringent quality control checks in place.

Furthermore, an express turnaround service is available for those times when practitioners need a restoration swiftly, and the laboratory also offers freepost on all standard orders.

More information about CosTech Dental Laboratory is available by visiting www. costech.co.uk or calling 01474320076.

SPECTACULAR IMPRESSION MADE BY DENTSPLY SIRONA

At the 2019 International Dental Show (IDS), Dentsply Sirona engaged in indepth discussions with customers and partners. Their survey ' 1 profession. 1000 jobs.' provided a great starting point for this - numerous visitors to the booth took part at www.1profession1000jobs. com, and the results confirmed beyond doubt that, in addition to treating patients, dentists and dental technicians perform a whole range of other tasks. The company received a wealth of feedback from the countless discussions held at the booths.

As a token of appreciation, visitors were presented with a Dentsply Sirona rubber duck: 'Resto Rebecca,' 'Preventive Preston', 'Lab Lara' and their brightly coloured colleagues soon became the stars of the tradeshow. The cheerful ducks, featuring a dental design, almost became collectors' items and, at the end of the five-day tradeshow, more than 12,000 ducks had found a new home.

The products presented, such as Primescan and Surefil one, play a key role in helping dentists and dental technicians provide their patients with optimal treatment. The Dentsply Sirona team, wearing matching blue and orange sneakers, demonstrated a unified spirit in presenting Dentsply Sirona as a customer-centric company.

Over 14,000 demonstrations were held to explain the new products and how they function to visitors to the booths. In addition, more than 3,000 dentists and dental technicians took the opportunity to participate in training events. The focus here was on treatment plans for endodontics as well as issues relating to digital imaging and dental technology.

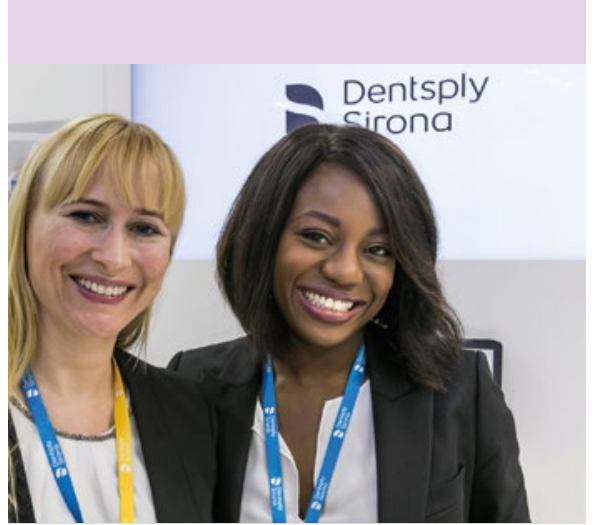

